\title{
The Modernization of Isan Folk Performance (Morlum): A Change for Survival
}

\author{
Itsarate Dolphen \\ Department of Thai, Faculty of Humanities and Social Sciences, Khon Kaen University, Thailand
}

Copyright $\bigcirc 2016$ by authors, all rights reserved. Authors agree that this article remains permanently open access under the terms of the Creative Commons Attribution License 4.0 International License

\begin{abstract}
Isan folk performance or Molum is about the folk singing performance narrated by the verse of song composing of words, rhyming with different styles of singing from the beginning of performance to the end of performance. This folk performance has been deep-rooted for many decades in the Northeast Thailand. However, it cannot maintain its traditional styles of performance as it used to be in the past. As for the postmodern era, it is necessary for the owner of Morlum band to adapt his or her performance up-to-date and being attractive to the audience. The question is what modernity in this age is incorporated into this folk performance and which factor is considered as the main factor causing this modernity happen. This paper aims to analyse the modernization of Isan folk performance in the Northeast Thailand. How Isan folk performance adapts itself to the postmodern era to maintain its cultural root will be studied. In this paper, the factors that force this folk performance into modernity will be described as well. The data used in this paper were collected from the four famous Isan folk performances (Morlum troupe) in Northeastern Thailand namely: Rattanasilapa Intathaiyaraj, Rabiab Watasilapa, Prathom Bantheongsilapa, Silapinphuthai. The observation and in-depth interviews of Morlum performers are the key qualitative methods employed in this study. And the modernization theory is proposed as a conceptual framework to analyse the social phenomenon and a new technology incorporated in this folk performance. The findings reveal that All Morlum bands in particular have developed their traditional folk performance into a modern style by incorporating a social phenomenon and new technology into their performances. It has been found that all three main parts of the particular folk performance namely: a luk thung performance, a comedy show and a lumruengtorklorn or 'storytelling' with special rhythmic and melodious music, are modernized in order to attract the audiences and to maintain their folk culture. The modernization incorporated into Isan folk performance can be analysed into many aspects such as the rhythmic and melodious music, the Isan folk songs, the storytelling, the modern stage of performance, the light and sounds, the new high technology of the performance and so on and so forth. The most important factor that forces this folk performance changing to modernization is the financial factor.
\end{abstract}

Keywords Modernization, Isan Folk Performance, Change, Survival

\section{Introduction}

Isan folk performance or Molum is well-known as one symbol of Isan cultural heritage. It is a folk performance which shares many similarities with the folk performance of the Lan Xang that include three widely dispersed centers of power connected by the Maekhong River as follows: Champasak in the south, Vientiane in the center, and Luang Phrabang in the north. It is about the folk singing performance narrated by the verse of song composing of words, rhyming with different styles of singing from the beginning of performance to the end of performance. This folk performance has been deep-rooted for many decades in the Northeast Thailand. However, it cannot maintain its traditional styles of performance as it used to be in the past. The traditional styles of Isan folk performance right now have been changed a lot from the past. As for the postmodern era, it is necessary for the owner of Morlum band to adapt his or her performance up-to-date and being attractive to the audiences. There are many techniques of modern performances to be incorporated in Isan traditional performance. The question is what modernity in this age is incorporated into this folk performance and which factor is considered to be the main factor causing this modernity happened.

Therefore, this paper aims at analysing the modernization of Isan folk performance in the Northeast Thailand and studying how Isan folk performance adapts itself to the postmodern era to maintain its cultural root. In this paper, the factors that force this folk performance into modernity will be described as well.

\section{Data Collection}

The data used in this paper were collected from the four famous Isan folk performance bands (Morlum troupe) in Northeastern Thailand namely: Rattanasilapa Intathaiyaraj, Rabiab Watasilapa, Prathom Bantheongsilapa, and 
Silapinphuthai. These Morlum bands were performed at Beung Kaennakorn, Khon Kaen Thailand during the end of Buddhist lent festival. They started their show from $9.00 \mathrm{pm}$. and then ended the show around $1 \mathrm{am}$ in. The observation and in-depth interviews of Morlum performers are the key qualitative methods employed in this study. There are five performers of each Morlum bands which were selected as the key informants of in-depth interviews. For the framework of this study, the modernization theory is proposed as a conceptual framework to analyse the social phenomenon and a new technology incorporated in this folk performance.

\section{The Modernization Theory and the Process of Changes in Isan Folk Performance}

The modernization theory is used to explain the process of modernization within societies. This theory looks at the internal factors of a country that may cause the changes to societies. It is believed that the traditional country can be developed in the same manner as the developed counties have. This theory concerns about the process of transformation from traditional countries or undeveloped countries to modern cities. For this study, this theory is adapted to explain the Isan folk performance in terms of how the traditional styles of Isan folk performance are changed to the modern style of Isan folk performance. The concept of this theory will be used to criticize not only the process of changes, but also the response to those changes. In addition, this theory also looks at internal dynamics while referring to social and cultural structures and the adaptation of new technologies.

The modernization theory can be used to analyze the process of changes in Isan folk performance as mentioned. The changes can occur in many aspects of the performance such as the rhythmic and melodious music, the musical instruments, the story of performance, and so forth. The process of social changes affects the process of changes in Isan folk performance.

\section{Results}

Under this section, the modernization of Isan folk performance will be illustrated first and then the factors that force this folk performance into modernity will be described later.

The findings of this study reveal that All Morlum bands in particular have developed their traditional folk performance into a modern style by incorporating a social phenomenon and new technologies into their performance. It has been found that all three main parts of the particular folk performance namely: a luk thung performance, a comedy show and a lumruengtorklorn or 'storytelling' with special rhythmic and melodious music, are modernized in order to attract the audience and to maintain their folk culture. The modernization incorporated into Isan folk performance can be analysed into many aspects such as the rhythmic and melodious music, the Isan folk songs, the storytelling, the modern stage of performance, the light and sounds, the new high technology of the performance and so on and so forth. The modernization incorporated into Isan folk performance can be discussed below.

\section{The modernization of Isan folk performance}

The modernization of Isan folk performance can be grouped and discussed into five categories as follows:

1) The modernization of rhythmic and melodious music

If we compare the rhythmic and melodious music of Isan folk performance in the past with that in the present time, it will be found that the traditional style of rhythmic and melodious music of Morlum in this age has been changed a lot. The performance nowadays is geared to be appropriate with audiences' affection. The rhythmic and melodious music of Isan folk performance in the past shows Isan's identity of traditional music which shares the similarity of melodious music with Lao PDR. But the rhythmic and melodious music nowadays is composed in very modern style similarly to Western music with modern musical instruments such as electric guitars, organs, trumpets, saxophones, drums and keyboard instruments associated with Isan folk musical instrument named Kaen or Isan mouth organ. Kaen is the traditional musical instrument made of bamboo creating a sound similar to that of the violin and Phin or three-stringed lute with a pear-shaped body plucked by pick of the right hand while playing. The modern musical instruments just mentioned are mainly used in Isan folk performance or Morlum in order to perform a sharp rhythm while playing the music. The Western musical instruments play harmoniously with Isan folk instruments in Isan folk songs.

2) The modernization of Isan folk songs

Isan folk songs are ones that show a modernity of Isan folk performance. In the past, Isan folk songs were not considered as a main part of this particular performance. They were added to be a part of Isan folk performance about thirty years ago. In this day and age, Isan folk songs play an important role in the performance as one main part of Morlum named a luk thung performance and also incorporated in the lumruengtorklorn. The Isan folk songs are different from those in the old days as they are composed with new contents of modern society even based on the same theme of love or Isan's ways of life. These folk songs are played with modern musical instruments associated with traditional Isan musical instruments as mentioned. As for the content of Isan folk songs today, some of them reflect Isan labors working in industrial factories in the big city like Bangkok. These Isan labors have to leave their hometown for modern city and work hard for a better quality of life. 


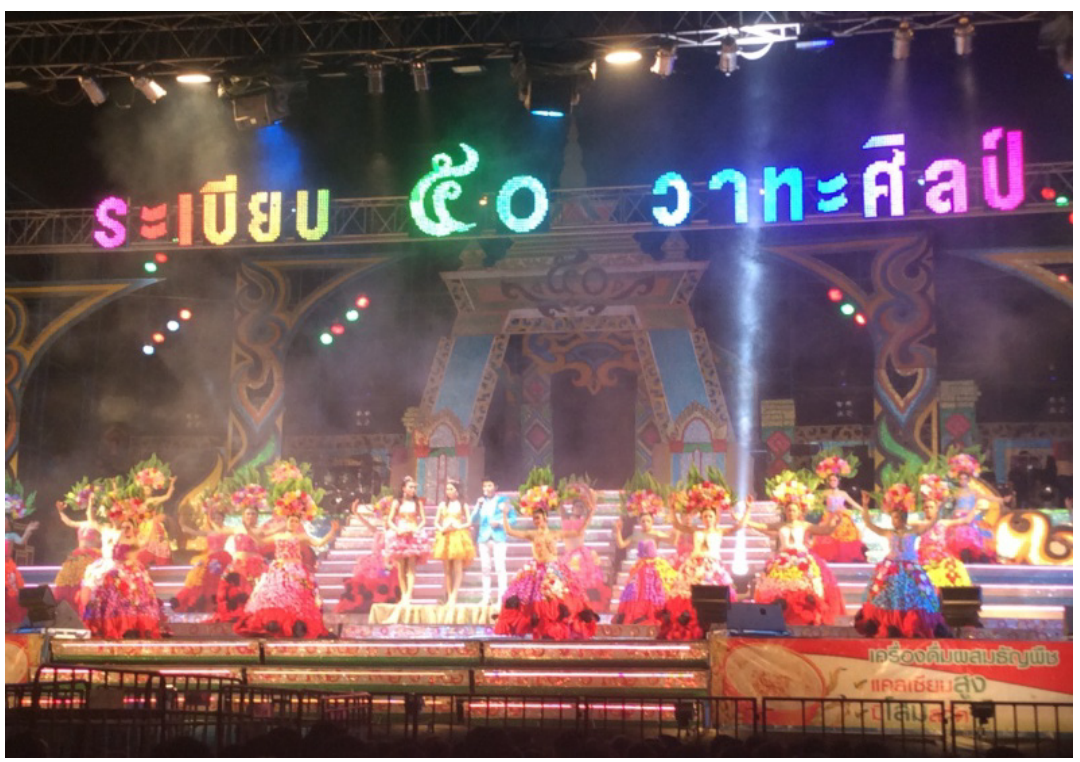

Figure 1. Isan folk songs always performed with a troupe of modern dancers

The figure 1 is taken from Rabiab Watasilapa band to show the modern Isan folk songs. Isan folk songs are performed with a troupe of modern dancers. The dancers are both male and female. They will dress with colorful and beautiful costumes to attractive the audiences. Some costumes are designed in the same style as the modern performances do. The costumes are designed differently in harmonious with the lyrics of Isan folk songs.

3) The modernization of the storytelling

The storytelling which is the main part of this folk performance is changed a lot from the past. In the previous day, Isan folk tales were selected to be performed in Morlum. Even all Isan people knows those folktales very well, they still love watching them. For the current years, Isan folk tales are not selected as theme of performance but new stories which are associated with current society are invented and performed. For an example, a story of Isan ladies getting married with foreigners is one of modern stories performed in Morlum. This kind of stories reflects a modernization of Isan society. People are easily involved in the performance because they see lots of Isan ladies getting married with foreigners in their village. Sometimes, this phenomenon is illustrated in terms of a mockery to show that getting married with foreigners cannot help their quality of life to be better. Therefore, if we have a chance to watch Morlum or lumruengtorklorn, we often watch the new story that reflects some problems of current society such as social problems and economic problems.

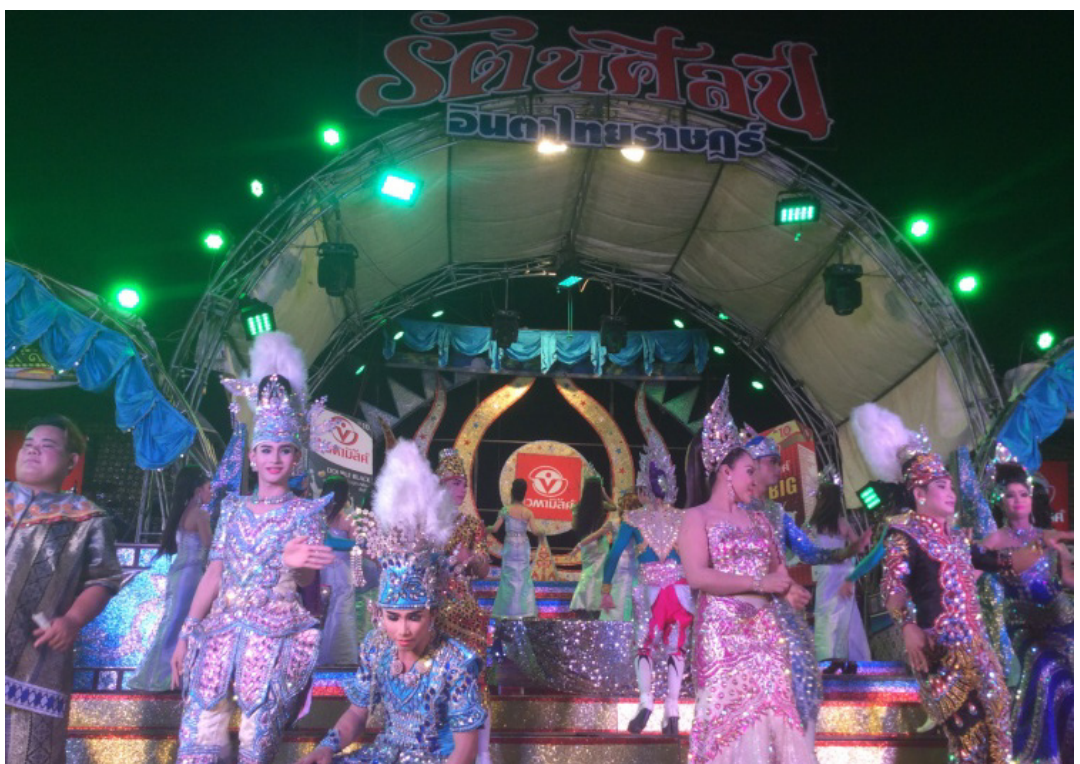

Figure 2. Morlum performers with traditional costumes influenced by Likay

The figure 2 is taken from Rattanasilapa Intathaiyaraj band. Even Morlum performers play a modern story not a folktale; they always dress in the traditional costumes influenced by Likay's extravagant costumes. Likay is a folk performance from 
the Central of Thailand. This performance is famous for its flamboyant costumes. Both men and women do heavy make-up and wear fake jewels. All major characters in performing lumruengtorklorn always dress up with these beautiful costumes.

4) The modernization of the modern stage of performance

In the old days, Morlum was performed on the ground which is totally different from the present days. Morlum performers right now play on a modern stage. This stage is 6 feet high with approximately 20 meters long and 8.5 meters wide. The stage of each Morlum band will be decorated with Isan and Thai traditional painting and arts. All sponsors of each Morlum band will be presented and decorated as part of the stage as shown in the following figure.

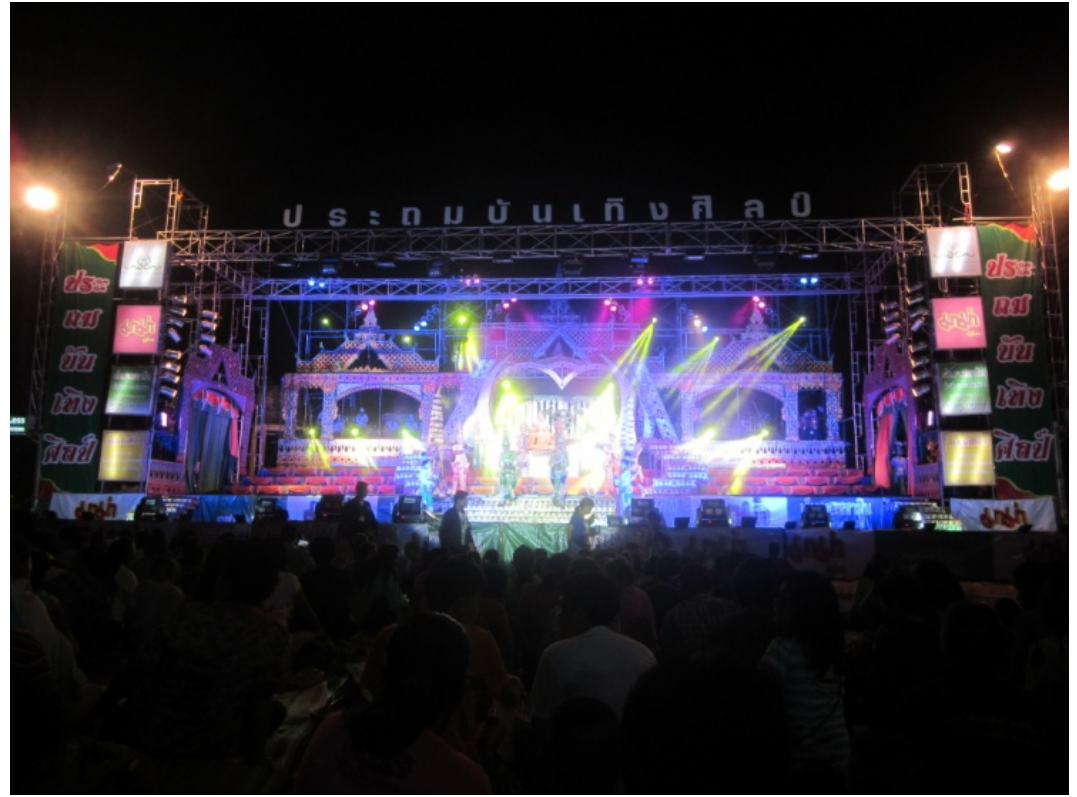

Figure 3. The Morlum stage of Prathom Bantheongsilapa

The figure 3 shows the Morlum state of Prathom Bantheongsilapa band which is built up with Isan painting and arts. The sponsors are presented as part of the stage on the left and right sides of the stage.

5) The modernization of the light and sounds

The light and sounds are very important factors to attract the audience to watch the performance. The more spectacular light and sounds, the more people love watching it. It has been found that All Morlum bands are competitive in light and sounds. They use high technology to create an attractive show. The following figure shows how astonishingly creative light and sounds of Morlum performance.

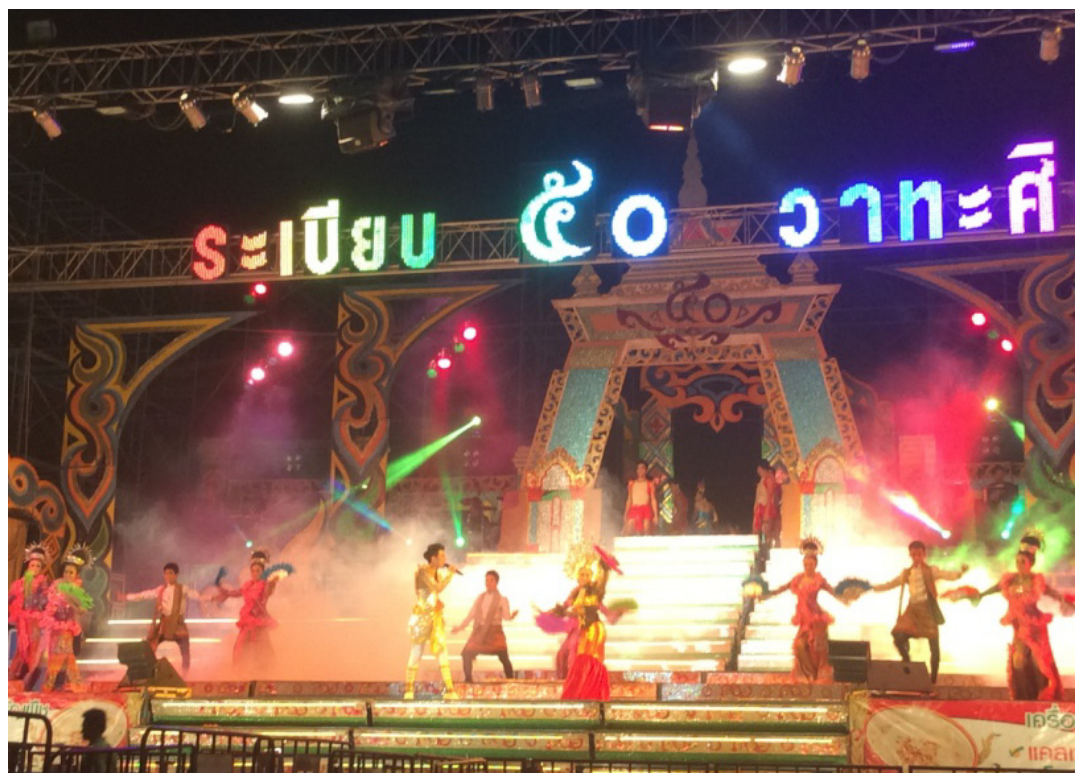

Figure 4. The light and sounds presented in Morlum performance 
As we can see form the figure 4 taken from Rabiab Watasilapa band, the high technology of light and sounds is proposed as a key factor to attractive the audiences. The spectacular lights make the show look wonderful and outstanding.

2. The factor that forces Isan folk performance into modernity

Based on my in-depth interview, it is found that there are two major factors that force Isan folk performance into modernity. Both of them can be discussed as follows:

1) Financial factor

The most important factor that forces this folk performance changing to modernization is the financial factor. As more than one hundred people of performers and staff in each Morlum troupe to be taken care only by the owner of Morlum band, it is needful for each big troupe itself to be invited by the hosts many times a year within a season of performing. If Morlum is often invited to perform, it means that the last breath of Morlum performers is prolonged.

2) Social change factor

Social change is another factor that forces Isan folk performance into a modern performance. As Isan society is a dynamic and modern society, some old identities including Isan folk performance is shaped into a modern style in order to serve people's need. Many old traditions of Isan folk performance as mentioned previously are left behind for its life. If Morlum bands do not adapt themselves for new society, they may be vanished from Isan society.

\section{Conclusions}

Isan folk performance or Morlum nowadays has developed itself into Isan modern folk performance. All changes are geared to modernization for attracting the Morlum audience, for maintaining Isan cultural heritage and for their own survival. The modernization of Isan folk performance can be described as the modern of rhythmic and melodious music, the modern of of Isan folk songs, the modern of the storytelling, the modern of the modern stage of performance, and the modern of the light and sounds. As for the factors that force Isan folk performance into modernity, it can be stated that the financial factor is the main stream of forcing its changes into modernization.

This study is beneficial for those who are interested in cultural studies and for those who want to vitalize the traditional folk performance which is being replaced by a modern style of performance and a new technology of globalization remaining in society. This study is also significant for being studied as the case study of how Morlum performers combine a traditional way of folk performance with a modern style of life to remain harmoniously.

\section{REFERENCES}

[1] Cook, Nicholas. 2000. Music: A Very Short Introduction. Hong Kong: Oxford University Press.

[2] Gavrov, Sergey. 2005. "The phenomenon of modernization". Filozofia bliższa życiu: Wyższa Szkota Finansów $i$ Zarzqdzania in Warsaw.

[3] Inglehart, Ronald \& Welzel, Christian. 2005. Modernization, Cultural Change and Democracy: The Human Development Sequence, New York: Cambridge University Press.

[4] Lueboonchu, Supanni. 1999. Isan Folk Music and Performance Art. Faculty of Humanities and Social sciences, Mahasarakham University.

[5] McGuigan, Jim. 2006. Modernity and postmodern culture. Open University Press: Buckingham.

[6] Miller, Terry E. and Sean Williams. 2008. The Garland Handbook of Southeast Asian Music. New York: Routledge.

[7] Morton, David. 1976. The Traditional Music of Thailand. Berkeley: University of California Press.

[8] Sukphisit, Suthon. 1997. The Vanishing Face of Thailand. Bangkok: The Post Publishing Public Company Limited. 